
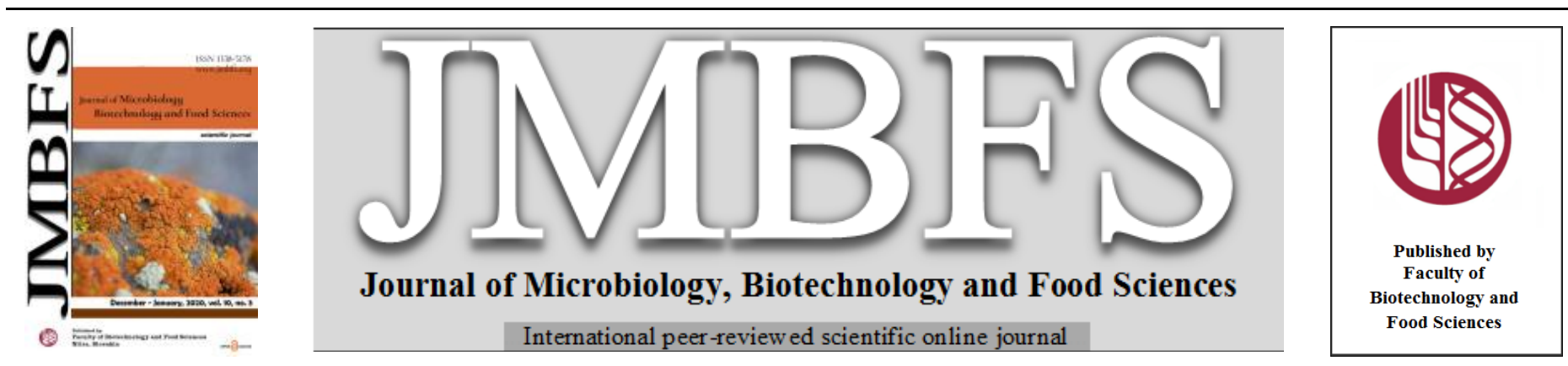

\title{
ENCAPSULATION OF POMEGRANATE SEED OIL USING W/O/W NANO-EMULSION TECHNIQUE FOLLOWED BY SPRAY DRYING AND ITS APPLICATION IN JELLY FORM
}

\author{
Marwa Hanafy Mahmoud ${ }^{*}$, Fathy Mohamed Mehaya ${ }^{l}$ and Ferial Mohamed Abu-Salem ${ }^{l}$
}

$\operatorname{Address(es):~}$

${ }^{1}$ National Research Centre, Food Technology Dept., El-Bohous St., Dokki, Cairo, Egypt.

*Corresponding author: marwahanafy78@yahoo.com

doi: 10.15414/jmbfs.2020.10.3.449-453

\section{ARTICLE INFO}

Received 31. 3. 2020

Revised 25. 8. 2020

Accepted 23. 9. 2020

Published 1. 12. 2020

Regular article

OPEN $\partial_{\text {Access }}$

\begin{abstract}
Punicic acid, which is an $\omega-5$ polyunsaturated fatty acid representing the main component of pomegranate seed oil (PSO) with pharmaceutical and food usages, is susceptible to oxidation. Also, its water insoluble properties allow only few fractions to be absorbed. Therefore, the protection of this oil as well as bioavailability and good abortion properties are the aim of our work. Formation of water in oil in water (W/O/W) emulsion from pomegranate seed oil followed by spray-drying resulted in its transformation to nanoencapsulated oil powder whose nano-capsules had a narrow size distribution and small diameters in addition to zeta potential of about $-22.9 \mathrm{mV}$. Thus, the oil-loaded system was assumed to be stable. Scanning electron microscope (SEM) measurement has confirmed the presence of surface pores which allow higher air permeability of powder, consequently a higher solubility and release was predicted. Addition of the obtained nano-encapsulated oil to jelly had a good sensory attribute and acceptability. In conclusion, pomegranate seed oil can be consumed as nano-capsules in jelly form with better water-soluble properties and it was predicted to have good absorption with expected great bioavailability.
\end{abstract}

Keywords: pomegranate seed oil, punicic acid $\omega-5, \mathrm{~W} / \mathrm{O} / \mathrm{W}$ nano emulsion, encapsulated oil, jelly form

\section{INTRODUCTION}

Fruit processing generates a huge amount of fruit waste and by-products annually worldwide which lead to serious industrial and environmental problems. So, maximizing the reuse of fruit waste and by-products are of great demands for food manufactures. In this respect, fruit by-products may be used as good sources of bioactive and nutritional ingredients for the production of functional foods Pomegranate is considered one of the tropical fruits widely grown in many countries (Fadavi et al., 2005). Pomegranate juice containing high amount of phenolic compounds such as anthocyanin, which has strong antioxidant activities (Mahmoud et al., 2017), in addition it has the potential for exploration of broader applications as good candidate for functional foods and as nutraceutical plant based products (Fouad et al., 2015). During the last few years, there are many pomegranate industrial products such as juice, jelly and jam that could produce great amounts of by-products like peels and seeds (Seeram et al., 2005). Seeds account for approximately $22 \%$ of the total wastes (rind plus seed) of pomegranate juice industries (FAO, 2011; Abid et al., 2017). Pomegranate seed is rich in oil that accounts for $20 \%$ of the seed weight and contains more than 95\% triglycerides (Lansky and Newman, 2007). This oil contains punicic acid, approximately $80 \%$ (9c,11t,13c-18:3), linoleic acid, palmitoleic acid, palmitic acid, steric acid and arachidic acid (Hornung $\boldsymbol{e t}$ al., 2002). Punicic acid is a conjugated linolenic acid (18:3n-5) that belongs to the class of polyunsaturated fatty acids. Punicic acid has many health benefits due to its antioxidant and antiinflammatory properties (Jing et al., 2012). Cytotoxicity for tumor cells by pomegranate seed oil was examined in both mouse and human monocytic leukemia cells (Suzuki et al., 2001) and it was found to be anticarcinogenic (Lansky and Newman, 2007). Also, it possesses strong antiobesity, antidiabetic, and antiproliferative effects as well as its significant effect on lipid metabolism (Aruna et al., 2016). These physiological effects make pomegranate seed oil of a great therapeutic potential, although more researches are needed to confirm the previous findings (De-Melo et al., 2014). Since punicic acid is highly susceptible to oxidation, addition of antioxidants is very important to increase its stability. But unfortunately, addition of antioxidant was found to decrease its antitumor activity. Also, the lake of solubility of pucinic acid in water leads to absorption of only a minor fraction of it. Considering these previously mentioned characters, limited bioavailability of punicic acid is being a restricted factor that lowers its applications. Consequently, several trials were done to increase its applications including cyclodextrin inclusion, microencapsulation and mixing with edible oils or fats.

The application of encapsulation technology in functional food represents a novel area for researches. Nano-encapsulation of bioactive compounds could improve their dietary uptake, absorption and bio-availability of supplementary nutrients compared to ordinary sources (Mohammadi et al., 2016).

Since, punicic acid is extremely susceptible to oxidation and insoluble in water. Therefore, the aim of this study is to increase solubility and, accordingly, to increase absorption and bio-availability as well as good protection of pomegranate seed oil by nano-encapsulation after the formation of double emulsion $\mathrm{W} / \mathrm{O} / \mathrm{W}$ and its application as a dietary supplement in the form of jelly.

\section{MATERIALS AND METHODS}

\section{Preparation of pomegranate seed oil}

Plant material: Pomegranate granatum fruit was purchased from local market, Cairo, Egypt at season 2018. Pomegranate seed oil was prepared as follows; after juice extraction, seeds were obtained then dried in air-oven at $40{ }^{\circ} \mathrm{C}$. About 100 gm seeds were ground and extracted in duplicate with $2000 \mathrm{ml}$ hexane at room temperature overnight. Then, the hexane was removed with a rotary evaporator at $40{ }^{\circ} \mathrm{C}$ under vacuum and the extract was dried to a constant weight then, it was stored at $-18^{\circ} \mathrm{C}$ in the dark until being used.

\section{Characterization of pomegranate oil fatty acid profile by GC-MS}

The derivatization of fatty acids was preformed according to Rozes et al., (1993) Briefly, aliquot $20 \mathrm{mg}$ of pomegranate oil was replaced into screw-capped tube and $1 \mathrm{ml}$ of $1 \%$ sodium methoxide in methanol was added, then it was homogenized in a vortex for $20 \mathrm{sec}$. Then, $1 \mathrm{~mL}$ of hexane was added which led to separation of two layers, saponified (fatty acids) and unsaponified compounds; the organic layer (fatty acids) was collected, dried over anhydrous $\mathrm{Na}_{2} \mathrm{SO}_{4}$ and injected into GC-MS (Gas chromatography-mass spectrometry).

The GC-MS system (Agilent Technologies) gas chromatograph (7890B) was equipped with mass spectrometer detector (5977A), Central Laboratories Network, National Research Centre, Cairo, Egypt. The GC was equipped with HP-5MS column ( $30 \mathrm{~m} \times 0.25 \mathrm{~mm}$ internal diameter and $0.25 \mu \mathrm{m}$ film thickness). Analysis was carried out using helium as the carrier gas at a flow rate of 1.0 
$\mathrm{ml} / \mathrm{min}$, injection volume of $1 \mu \mathrm{l}$ and the following temperature program: $50{ }^{\circ} \mathrm{C}$ for $1 \mathrm{~min}$; rising at $20^{\circ} \mathrm{C} / \mathrm{min}$ to $200{ }^{\circ} \mathrm{C}$ and held for $5 \mathrm{~min}$; rising at $3{ }^{\circ} \mathrm{C} / \mathrm{min}$ to $230{ }^{\circ} \mathrm{C}$ and held for $23 \mathrm{~min}$. The injector and detector were held at $250{ }^{\circ} \mathrm{C}$. Mass spectra were obtained by electron ionization (EI) at $70 \mathrm{eV}$ and using a spectral range of $\mathrm{m} / \mathrm{z} 20-550$ and solvent delay $1.8 \mathrm{~min}$. Identification of different constituents was determined by comparing the spectrum fragmentation pattern with those stored in Wiley and NIST Mass Spectral Library data.

\section{Nano-emulsion preparation}

W/O/W nano-emulsion was prepared by spontaneous emulsification according to (Assadpour et al., 2017) with some modification. Briefly, biopolymer solution was prepared; Arabic gum powder and maltodextrin ( $25 \mathrm{~g}$ each) were dissolved separately in boiling deionized water to prepare $200 \mathrm{ml}$ solution. At the same time, aqueous solution of whey protein concentrate $(50 \mathrm{~g})$ was prepared by dispersing required amounts of whey protein (WPC) powder into $200 \mathrm{~m}$ deionized water. Then, all prepared solutions were gently stirred for at least 30 min on a magnetic stirrer, then they were mixed together and stored overnight at room temperature for full hydration of biopolymers. The emulsion was prepared by mixing of biopolymer solution and Span 80 solution and then added oil as drop wise to the solution at high speed homogenization $(20000 \mathrm{rpm})$ using a mechanical homogenizer (CAT, Unidrive 1000 D, M.Zipperer GmbH, Germany) followed by prop-ultrasonic (SONICS, Vibra-cell, VCX750, USA)

\section{Spray drying of W/O/W emulsion}

The prepared emulsion solution was transformed into encapsulated powder by spray drier (B-290, Buchi) equipped with a pressure air atomizing nozzle at 2.5 bar air pressure, inlet air temperature of $180 \pm 5^{\circ} \mathrm{C}$, and outlet air temperature of $90 \pm 5{ }^{\circ} \mathrm{C}$ with a feed flow rate of $450 \mathrm{ml} / \mathrm{h}$. The dried powder was collected and stored in dark bottle, air tight containers at $4^{\circ} \mathrm{C}$ until further analysis.

\section{Encapsulation efficiency measurement}

The encapsulation efficiency was determined by calculating the difference between the amount of oil at the surface against encapsulated oil in capsules as described by Calvo et al., (2010). Briefly, $5 \mathrm{~g}$ of microcapsules were washed with $50 \mathrm{ml}$ hexane under magnetic stirrer at $200 \mathrm{rpm}$ for $60 \mathrm{sec}$. After $10 \mathrm{~min}$, the mixture was filtered through filter paper (No. 41, Whatman, Maidstone, UK). The powder residue was again washed twice with $5 \mathrm{ml}$ of hexane. Hexane was evaporated to constant weight by oven at $105{ }^{\circ} \mathrm{C}$. The total oil content was extracted by Soxhlet extraction of microcapsules using $250 \mathrm{ml}$ hexane for $5 \mathrm{~g}$ of powder for $4 \mathrm{~h}$. The encapsulation efficiency was calculated by the following equation:

Encapsulation efficiency $(\%)=($ Total oil content - Surface oil content $) /($ Total oil content) $\times 100$

\section{Droplet size measurement}

Droplet size (particle size and zeta potential) of pomegranate nano-oil was analyzed using a dynamic light scattering method (Zeta-sizer Nano Zs, Malvern Instrument, Malvern, UK). To avoid multiple scattering, all samples were diluted by water. For microstructure analysis, a Zeiss optical microscope (Germany) was used and the obtained images were analyzed using Image J Software (Hosseini $\boldsymbol{e t}$ al., 2015).

\section{Scanning electron microscopy of encapsulated powders}

The nano-encapsulated powder was sprinkled onto a two-sided adhesive tape and then coated with a thin layer of gold. Morphological features of particles were then observed by a field emission scanning electron microscope (S- 4160 Cold Field-Emission SEM, QUANTA, FEG 250, Thermo Fisher Scientific, USA) with an accelerated voltage of $320 \mathrm{kV}$ and photographed at 6000 .

\section{Fourier transform infrared spectroscopy (FTIR)}

The structure analysis of the samples was examined by Fourier transform infrared spectroscopy (FT-IR). The IR spectra of the samples were recorded by FT-IR 6000 spectrometer (JASCO, Japan). The spectrum was scanned in transmission mode from 400 to $4000 \mathrm{~cm}^{-1}$ wavenumber. The dry samples were blended with $\mathrm{KBr}$ powder and pressed into a disk before spectrum acquisition.

\section{Application in jelly form}

Jelly powder was prepared according to (Mahmoud $\boldsymbol{e t}$ al., 2017) with some modification. Samples were prepared with added encapsulated oil at concentrations of $2.5,5,7.5$ and $10 \%$, while control sample was a commercial jelly powder. The treatments were first prepared by mixing $20 \mathrm{gm}$ of gelatin powder and $75 \mathrm{gm}$ of sugar with encapsulated oil, $0.1 \mathrm{gm}$ of colors and $1 \mathrm{gm}$ of strawberry essence powder. Next, $200 \mathrm{ml}$ hot water was added to the powder in a mixing bowl and the solution was adjusted with $20 \%$ citric acid solution to $\mathrm{pH}$ of 4.3 at which point the preservative sodium benzoate $(0.05 \%)$ was added Prepared jelly with different concentrations of the added encapsulated oil was stored in a $4{ }^{\circ} \mathrm{C}$ refrigerator and sensory evaluated to determine the more preferred level of added concentration.

\section{Sensory evaluation}

Sensory evaluation was conducted in the Food Technology Department, National Research Centre, Egypt. Twenty trained panelists aged between 25 and 40 years were selected to take part in the sensory panel. The panelists measured the selected critical jelly attributes such as color, flavor, texture, appearance, after taste and overall acceptability according to Mahmoud et al., (2017). Al evaluations were performed in a well-controlled laboratory. To determine the degree of like for jelly products $(9=$ like extremely, $5=$ neither like nor dislike, 1 = dislike extremely) according to Peryam and Girardot (1952).

\section{Statistical analysis}

The data obtained from the study was statistically subjected to analysis of variance (ANOVA) Snedecor and Cochran (1980). Data were presented as mean \pm standard deviation (SD). The least significant difference (LSD) value was used to determine significant differences between means using ASSIST version 7.7 beta. Values were considered significant at $\mathrm{p} \leq 0.05$.

\section{RESULTS AND DISCUSIONS}

\section{Pomegranate seed oil Fatty acid profile by GC-Mass spectrum}

Pomegranate seed is a rich source of oil with special characteristics, because it contains high percentage of punicic acid which is an omega-5 fatty acid. Results of the present study revealed that total lipids of the Egyptian $P$. granatum seed was $15.38 \%$ on dry weight basis. Previous studies have indicated approximately similar results. Fadavi et al., (2006) reported that lipid content in sour pomegranate was $14.83 \%$ while Melgarejo and Artes (2000) reported that the lipid content was $6.3-12.2 \%$ for sweet Spanish pomegranate. Table 1 shows the fatty acid composition of oil extracted from pomegranate seed. It can be noticed that unsaturated fatty acids represent $89.73 \%$ in pomegranate seed oil, where punicic acid $(\omega-5)$ is the predominant fatty acid $(64.91 \%)$ and punicic acid isomers named alfa and beta eleostearic acids were represented as 11.3 and 2.86, respectively. Palmitic acid is the major saturated fatty acid with low percentage (3.66 \%). Dadashi et al., (2013) reported that punicic acid is the main fatty acid identified by gas chromatography for the oil extracted from four Iranian commercial varieties of pomegranate seed and it was found in the range from $72.07 \%$ to $73.31 \%$. The difference in punicic acid percentage between our results and the results of Dadashi et al., (2013) may be attributed to pomegranate different varieties as well as different conditions of cultivation.

Table 1 Fatty acid composition of pomegranate seed oil by GC-Mass

\begin{tabular}{lll}
\hline Fatty Acid & Relative \% & Library \\
\hline palmatic acid Methyl ester & 3.66 & NIST14.L \\
cis-Linoleic acid methyl ester & 3.89 & NIST14.L \\
Oleic acid methyl ester & 5.91 & W9N11.L \\
stearic acid methyl ester & 3.86 & NIST14.L \\
pinucic acid methyl ester & 64.91 & W9N11.L \\
alfa- Eleostearic acid methyl ester & 11.3 & W9N11.L \\
beta- Eleostearic acid methyl ester & 2.86 & W9N11.L \\
11-Eicosenoic acid methyl ester & 0.86 & NIST14.L \\
Oleic acid amide & 2.72 & NIST14.L \\
$\sum$ CLA fatty acids & 79.07 & \\
$\sum$ Unsaturated fatty acid & 89.73 & -- \\
$\sum$ Saturated fatty acid & 7.52 & -- \\
\hline
\end{tabular}

\section{Water/Oil/Water emulsion}

Emulsions are one of the promising encapsulation and delivery technologies; they have advantages such as controlled release and chemical stability of encapsulated nutrients like minerals, vitamins, amino acids, polyphenols, bioactive compounds etc. (Ilyasoglu and El, 2019; Prichapan and Klinkesorn, 2014). Double emulsions have many food applications such as reducing fat content, improving fatty acid profile, encapsulation of functional components and reducing sugar/salt content of foods by increasing taste intensity. Water-oil-water emulsions are primarily used in food applications. In this study, formation of double emulsion $\mathrm{W} / \mathrm{O} / \mathrm{W}$ by getting the oil particles wrapping the WPC molecules was made, then it was covered by another layer of polymer to produce a bigger molecule. That emulsion was obtained by either WPC and span twenty to produce water in oil in 
water emulsion. This structure allows more protection of oil, as well as its transformation into more water soluble particles and allow addition of more water-soluble additives to the emulsion (Buyukkestelli, and El, 2019).

\section{Characterization of formulated Nano-capsules}

The role of $\omega$-polyunsaturated fatty acids and their delivery to the intestine in sufficient amount is beneficial due to its anti-inflammatory properties and accordingly, reduce the chronic diseases (Ilyasoglu and El, 2014). Therefore, characterization of the prepared biodegradable nanoparticles of pomegranate seed oil was done to predict the improvement in its stability and solubility.

\section{Droplet size measurement}

The Particle size and its distribution were measured using DLS (dynamic light scattering) method, which is the common and popular technique for determining nano droplet size distribution profile of suspension (Khazaei et al., 2014). The droplet size of the tested samples Figure 1 showed that oil-loaded polymer micelles had a narrow size distribution and small diameters (about $112 \mathrm{~nm}$ ). That small size caused by adsorption onto the surface of a system or interface surfactant reduces the surface free energy and consequently decreases interfacial tension between the lipid matrix and the aqueous phase and leads to easier disruption of particles during homogenization to form smaller particles (Soleimanian et al., 2018).

Zeta potential reflects the stability of emulsion systems (Soleimanian $\boldsymbol{e t}$ al. 2018). Also, Zeta potential reflects the repulsion strength between charged particles. Typically, achieving a good stability required a minimum zeta potential of $\pm 30 \mathrm{mV}$ for nano suspension electrostatically stabilized. Furthermore, $\pm 20 \mathrm{mV}$ zeta potential is sufficient in the case of the combination between electrostatic and steric forces. This is because the hydrophilic surfactant coat can improve the stability of emulsion by further hydration surface layer (Tamjidi et al., 2014). In this study, the polymer displayed a zeta potential of about $-22.9 \mathrm{mV}$, hence the oil-loaded polymer system was assumed to be stable. The oil-loaded polymer micelles had a great surface area because of the entrapment of polymer molecules, which may be accountable for the enhancement of the negative charge on the micelle's surfaces. It was reported that by relatively high surface charges, particles could reinforce each other with a strong electrostatic emulsion force, thus improved the stability of the system (Chen et al., 2012).
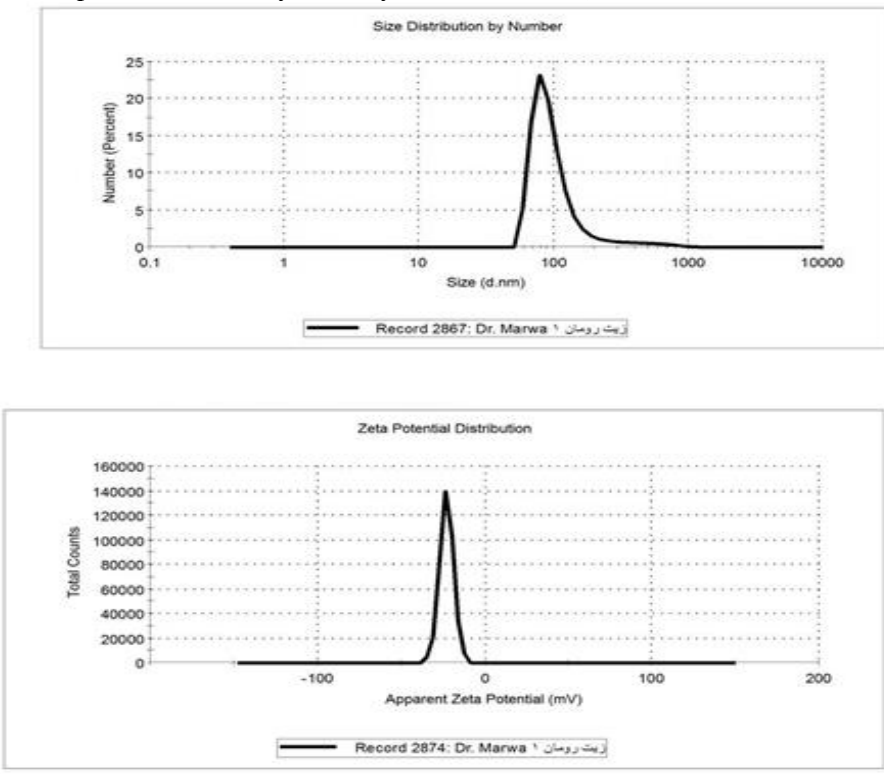

Figure 1 Zeta Size and Potential of nano encapsulated pomegranate seed oil.

Encapsulated powder morphology by Scanning electron microscopy and Encapsulation efficiency

Figure 2 reveals the SEM microphotographs of the powder containing encapsulated pomegranate seed oil with high content of $\omega-5$ punicic fatty acid Encapsulated powder consisted of WPC particles in the size of nano (about 112 $\mathrm{nm}$ ) wrapped with pomegranate seed oil layer and every group (about 2-4 molecules) of nano particles covered by another layer of polymer to produce a bigger particle (ranged from 200 up to $2000 \mathrm{~nm}$ ) as shown in Figure 2. Observations obtained from SEM confirmed the presence of surface pores obtained by emulsion matrix containing Span as a surfactant. This structure allowed great air permeability into the powder, while at the same time, much solubility and release are predictable due to higher surface area (Khazaei $\boldsymbol{e t}$ al., 2014 ; Jafari et al., 2007). Also, samples became with more smooth surfaces, rare cracks, and no dents which indicated a better protection of encapsulated oil and higher encapsulation efficiency $(85.75 \%)$ which is in accordance with those results obtained by Assadpour and Jafari (2017).

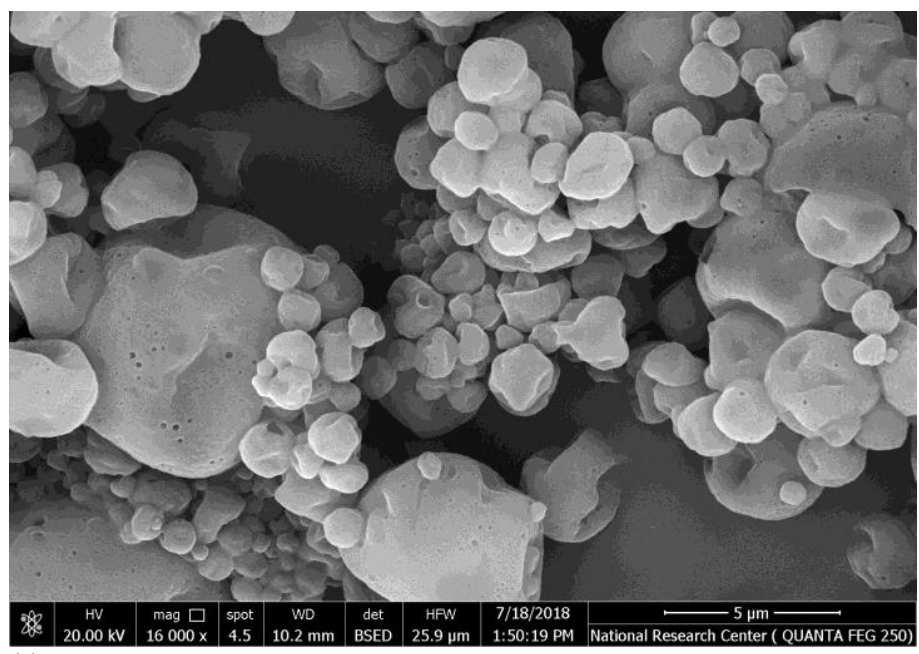

(a)

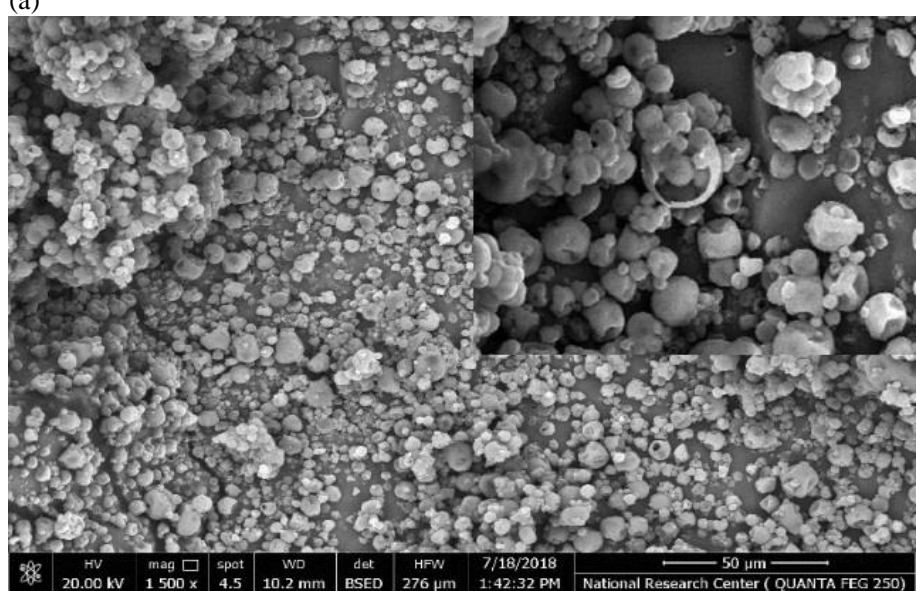

(b)

Figure 2 SEM microphotographs of: a) nano encapsulated pomegranate seed oil \& b) nano-oil particles with illustrating the structure of whey protein layer surrounded.

\section{Characterization of encapsulated powder by FTIR}

FTIR method is nondestructive technique for studying the functional groups of food matrices including oil. The FTIR spectra of pomegranate seed oil (PSO) and encapsulated PSO with whey protein/ gum Arabic/ Maltodextrin are illustrated in Figure 3. In PSO, the peak located at $3009 \mathrm{~cm}^{-1}$ corresponding to $\mathrm{C}-\mathrm{H}$ stretch which indicate to the double bond of an unsaturated fatty acid, while at 2925 and $2856 \mathrm{~cm}^{-1}$ the peaks correspond to the alkene and alkane stretch vibrations of hydrocarbon. These peaks had stronger intensity in pure oil than encapsulated ones. The peak around $990-980 \mathrm{~cm}^{-1}$ corresponds to the conjugated $\mathrm{C}-\mathrm{C}$ double bonds (cis and trans) in punicic acid and their isomers. Peaks located at 3400 and $1637 \mathrm{~cm}^{-1}$ in the FTIR spectra of encapsulated oil are attributed to the $\mathrm{O}-\mathrm{H}$ stretching, and asymmetric $\mathrm{N}-\mathrm{H}(-\mathrm{NH} 3+)$ of amide I. The amide I peak at $1637 \mathrm{~cm}^{-1}$ referred to the $\alpha$-helix of secondary structure of proteins in whey protein (Dybing and Smith, 1991). Moreover, the main ingredient of whey protein is $\beta$-lactoglobulin (apex 57\%) which provide emulsifying properties for their amphiphilic molecules that can increase emulsion stability and generate desirable characteristics of emulsions as well as decrease the interfacial tension between the hydrophilic and lipophilic phases (Sobhaninia et al., 2017). The peak at $1741 \mathrm{~cm}^{-1}$ represents to the carbonyl stretching group of the triacylglycerols in unsaturated fatty acids. 


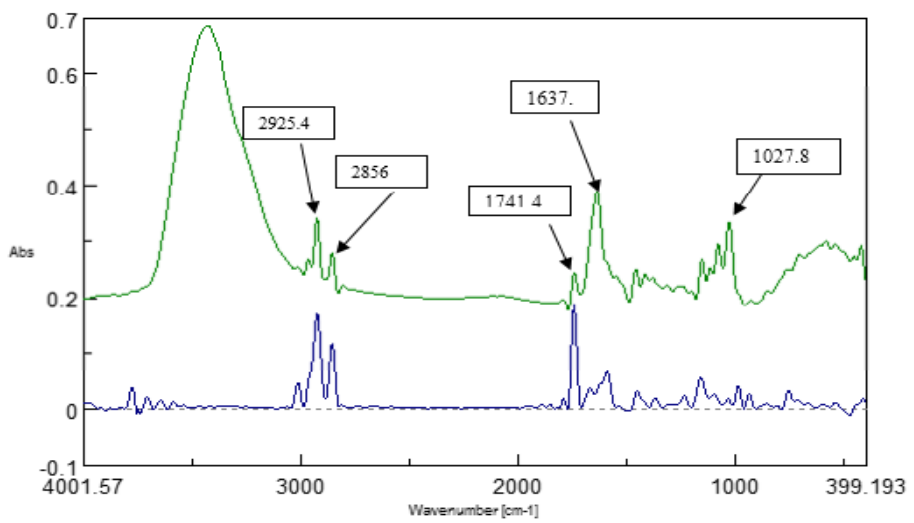

Figure 3 FTIR spectra of pomegranate seed oil (PSO) and encapsulated PSO.

\section{Jelly form of encapsulated oil}

The nano-encapsulation process is an alternative technique to increase the oil stability and allow its incorporation in foods with high water content. Addition of pomegranate seed oil in the form of nano-capsules to jelly was done to improve the bioavailability of the pomegranate seed oil. Jelly was selected as an application because it is a dietary supplement of a delicious taste and of high interest, especially for children. Figure 4 showed the jelly fortified with pomegranate seed oil nano capsules with different concentration of addition, comparing to control sample.

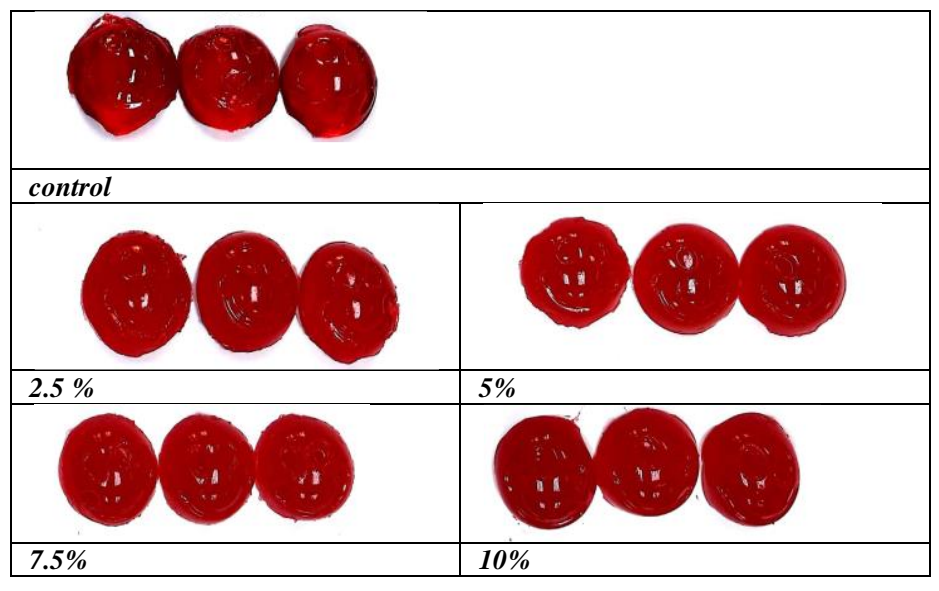

Figure 4 Jelly form of pomegranate seed oil Nano encapsulated.

\section{Sensory evaluation}

The sensory evaluation mean scores of parameters were statistically analyzed and the results are shown in Table 2. Results showed that no significant difference was found in both of color and texture between control and nano encapsulated pomegranate seed oil powder $(\mathrm{p}>0.05)$. On the other hand, sensory attributes which represented in taste, flavor and after taste showed significant differences between control and samples with nano pomegranate seed oil powder. The control sample and sample with pomegranate seed oil nano powder at a level of $2.5 \%$ had no significant difference in overall acceptability, while there was a significant difference $(\mathrm{p}<0.05)$ between them and samples with $5,7.5$ and $10 \%$ pomegranate seed oil nano powder. Regarding overall acceptability, the panelists preferred control sample and the sample produced with $2.5 \%$ pomegranate seed oil nano powder. Generally, it has been observed that the higher the percentage of the added powder, the more the sweet taste and the more pronounced the flavor of the added strawberry. Also, the higher the amount of added nano-powder, the greater the turbidity and lack of transparency (Figure 4).

Table 2 Sensory evaluation mean scores of parameters

\begin{tabular}{l|cccccc}
\hline Treatment & Color & Taste & Flavor & After taste & Texture & $\begin{array}{c}\text { Overall } \\
\text { acceptability }\end{array}$ \\
\hline Control & $8.28 \mathrm{a} \pm 1.17$ & $8.64 \mathrm{a} \pm 0.49$ & $8.46 \mathrm{a} \pm 0.49$ & $8.64 \mathrm{a} \pm 0.49$ & $8.1 \mathrm{a} \pm 0.9$ & $8.82 \mathrm{a} \pm 0.4$ \\
T1 & $7.2 \mathrm{a} \pm 0.98$ & $7.92 \mathrm{a} \pm 0.4$ & $7.56 \mathrm{ab} \pm 0.49$ & $8.1 \mathrm{a} \pm 0$ & $7.92 \mathrm{a} \pm 0.4$ & $8.28 \mathrm{a} \pm 0.4$ \\
T2 & $7.74 \mathrm{a} \pm 0.8$ & $6.84 \mathrm{~b} \pm 0.8$ & $7.02 \mathrm{~b} \pm 0.98$ & $6.66 \mathrm{~b} \pm 1.08$ & $7.38 \mathrm{a} \pm 1.17$ & $7.2 \mathrm{~b} \pm 0.64$ \\
T3 & $7.2 \mathrm{a} \pm 0.9$ & $6.66 \mathrm{~b} \pm 0.8$ & $6.66 \mathrm{~b} \pm 0.8$ & $6.84 \mathrm{~b} \pm 1.03$ & $7.38 \mathrm{a} \pm 1.17$ & $6.84 \mathrm{c} \pm 0.49$ \\
T4 & $7.38 \mathrm{a} \pm 1.17$ & $6.3 \mathrm{~b} \pm 0.00$ & $6.66 \mathrm{~b} \pm 0.49$ & $6.66 \mathrm{~b} \pm 0.8$ & $7.38 \mathrm{a} \pm 1.17$ & $6.48 \pm 0.4$ \\
LSD 5\% & 0 & 0.769 & 0.904 & 1.02 & 0 & 0.628 \\
\hline
\end{tabular}

- All values are means of triplicate determinations \pm standard deviation (SD).

- Means withincolumn with different letters are significantly different at $(\mathrm{P}<0.05)$.

\section{CONCLUSIONS}

The nano-form of pomegranate seed oil was encapsulated with whey protein Arabic gum and maltodextrin and Span as surfactant to improve its solubility, stability and bioavailability. The results of both zeta and electron microscope showed that the formed emulsion was water in oil in water $(\mathrm{W} / \mathrm{O} / \mathrm{W})$ with the formation of the two double layers surrounding the particles. Also, it showed that encapsulated powder consisted of pomegranate seed oil particles in the size of nano (about $112 \mathrm{~nm}$ ) covered by a layer of polymer, and every group of nano oil particle covered by another layer of polymer to produce a bigger particle in micrometer size (about 200-2000 nm). On the other hand, the encapsulated powder of pomegranate oil had narrow size distribution and small diameters and which was indicated to be stable emulsion by the analysis of droplet size with dynamic light scattering method, in addition to be completely soluble in water Also, it had a larger surface area which might be responsible for the enhancement of the negative charges on the micelle's surfaces. There were surface pores obtained by emulsion matrix, which can allow higher air permeability into powder, while a higher solubility and release is predicted. The obtained results lead to a good characteristic of encapsulated oil with water soluble properties and accordingly, more bioavailability. Finally, formation of nano-encapsulated oil in the jelly shapes made it easy and attractive to the consumer as a source of dietary supplement of punicic acid with regarded to better water-soluble properties and predicted good absorption and great bioavailability.

Acknowledgment: The work team is really thankful to the National Research Centre that has funded the project (grantee No: 11040110 / 2016-201) to allow for the potentiality to complete this research as a part of the project.
Funding statement: This work was supported by the National Research Centre, Giza, Egypt (Grant No:11040110 /2016-2019 National Research Centre) as a part of an ongoing project.

Competing interest statement: The authors declare no conflict of interest.

Originality of work : All data of this work is original data and not submitted before in any other journal.

Approving statement: All authors have read and approved the manuscript; and, that all are aware of its submission to JFST.

Ethical approve: The panelists were informed about the objectives of the study and their permission in the form of written consent was obtained. The study protocol was done in accordance with the guidelines stated by the Ethical Committee of the National Research Centre and it was approved by the committee $(16-4 / 2)$.

Additional information: No additional information is available for this paper.

\section{REFERENCES}

Abid, M., Cheikhrouhou, S., Renard, C.M., Bureau, S., Cuvelier, G., Attia, H., \& Ayadi, M.A., (2017). Characterization of pectins extracted from pomegranate peel and their gelling properties. Food Chem., 215, 318 325.https://doi.org/10.1016/j.foodchem.2016.07.181

Aruna, P., Venkataramanamma, D., Singh, A. K., \& Singh, R. P. (2016). Health benefits of punicic acid: a review. Comprehensive Reviews in Food Science and Food Safety, 15(1), 16-27.https://doi.org/10.1111/1541-4337.12171 
Assadpour, E., \& Jafari, S. M. (2017). Spray drying of folic acid within nanoemulsions: optimization by Taguchi approach. Drying Technology, 35(9), 11521160.https://doi.org/10.1080/07373937.2016.1242016

Assadpour, E., Jafari, S. M., \& Maghsoudlou, Y. (2017). Evaluation of folic acid release from spray dried powder particles of pectin-whey protein nano-capsules. International journal of biological macromolecules, 95, 238 247.https://doi.org/10.1016/j.ijbiomac.2016.11.023

Buyukkestelli, H. I., \& El, S. N. (2019). Development and characterization of double emulsion to encapsulate iron. Journal of Food Engineering, 263, 446453.https://doi.org/10.1016/i.jfoodeng.2019.07.026

Chen, B., Li, H., Ding, Y., \& Suo, H. (2012). Formation and microstructura characterization of whey protein isolate/beet pectin coacervations by laccase catalyzed cross-linking. LWT-Food Science and Technology, 47(1), 31 38.https://doi.org/10.1016/j.lwt.2012.01.006

Calvo, P., Hernández, T., Lozano, M., \& González-Gómez, D. (2010). Microencapsulation of extra-virgin olive oil by spray-drying: Influence of wall material and olive quality. European Journal of Lipid Science and Technology, 112(8), 852-858.https://doi.org/10.1002/ejlt.201000059

Dadashi, S., Mousazadeh, M., Emam-Djomeh, Z., \& Mousavi, S. M. (2013) Pomegranate (Punica granatum L.) seed: A comparative study on biochemica composition and oil physicochemical characteristics. International journal of Advanced Biological and Biomedical Research, 1(4), 351-363.

De-Melo, P.I.L., De-Carvalho, T., \& Mancini-Filho, J. (2014). Pomegranate seed oil (Punica granatum L.): a source of punicic acid (conjugated $\alpha$-linolenic acid). J Human Nutri Food Sci, 2(1), 1-11.

Dybing, S. \& Smith, D. (1991). Relation of chemistry and processing procedures to whey protein functionality: A review. Cult. Dairy Prod. J., 26 (1), 4-12.

Fadavi A, Barzegar M, Azizi MH. (2006). Determination of fatty acidsand tota lipid content in oilseed of 25 pomegranates varietiesgrown in Iran. J Food Compost Anal, 19, (6 - 7):676 - 680.https://doi.org/10.1016/j.jfca.2004.09.002

Fadavi, A., Barzegar, M., Azizi, M. H., \& Bayat, M. (2005). Note. Physicochemical composition of ten pomegranate cultivars (Punica granatum L.) grown in Iran. Food Science and Technology International, 11(2), 113 119.https://doi.org/10.1177/1082013205052765

FAO, 2011. Global Food Losses and Food Waste-Extent, Causes and Prevention. UN FAO, Rome.

Fouad, M. T., Moustafa, A., Hussein, L., Romeilah, R., \& Gouda, M. (2015). Invitro antioxidant and antimicrobial activities of selected fruit and vegetable juices and fermented dairy products commonly consumed in Egypt. Research journal of pharmaceutical biological and chemical sciences, 6(2), 541-550.

Hornung, E., Pernstich, C., \& Feussner, I. (2002). Formation of conjugated $\Delta 11 \Delta 13$-double bonds by $\Delta 12$-linoleic acid $(1,4)$-acyl-lipid-desaturase in pomegranate seeds. European Journal of Biochemistry, 269(19), 4852 4859.https://doi.org/10.1046/j.1432-1033.2002.03184.x

Hosseini, A., Jafari, S. M., Mirzaei, H., Asghari, A., \& Akhavan, S. (2015) Application of image processing to assess emulsion stability and emulsification properties of Arabic gum. Carbohydrate polymers, 126, 18.https://doi.org/10.1016/j.carbpol.2015.03.020

Ilyasoglu, H., \& El, S. N. (2014). Nanoencapsulation of EPA/DHA with sodium caseinate-gum arabic complex and its usage in the enrichment of fruit juice. $L W T$ Food Science and Technology, 56(2), 461468.https://doi.org/10.1016/j.lwt.2013.12.002

Jafari, S. M., He, Y., \& Bhandari, B. (2007). Effectiveness of encapsulating biopolymers to produce sub-micron emulsions by high energy emulsification techniques. Food Research International, 40(7), 862 873.https://doi.org/10.1016/j.foodres.2007.02.002

Jing, P., Ye, T., Shi, H., Sheng, Y., Slavin, M., Gao, B., Liu, L., \& Yu, L. (2012). Antioxidant properties and phytochemical composition of China-grown pomegranate seeds. Food Chem., 132, 1464.https://doi.org/10.1016/j.foodchem.2011.12.002

Khazaei, K. M., Jafari, S. M., Ghorbani, M., \& Kakhki, A. H. (2014). Application of maltodextrin and gum Arabic in microencapsulation of saffron petal's anthocyanins and evaluating their storage stability and color. Carbohydrate polymers, 105, 57-62.https://doi.org/10.1016/j.carbpol.2014.01.042

Lansky, E. P., \& Newman, R. A. (2007). Punica granatum (pomegranate) and its potential for prevention and treatment of inflammation and cancer. Journal of ethnopharmacology, 109(2), 177-206.https://doi.org/10.1016/j.jep.2006.09.006

Maha, H. Mahmoud,, Wahba, H. M., Marwa, H. Mahmoud, and Badawy, I. H (2017). Newly Formulated Antioxidant Rich Dietary Supplement in Jelly Form for Alleviation of Liver Disease in Rats. Journal of Biological Sciences, 17 (7), 334-346.https://doi.org/10.3923/jbs.2017.334.346

Mahmoud, M. H., Seleet, F. L., \& Foda, M. I. (2017). Effect of different concentration techniques in some properties of fresh and storage Pomegranate juice. Asian J Sci Res, 10(4), 290-298.https://doi.org/10.3923/ajsr.2017.290.298

Melgarejo P. Artes F. 2000. Total lipid content and fatty acidcomposition of oilseed from lesser known sweet pomegranateclones. J Sci Food Agric 80(10): 1452 0010(200008)80:10<1452::AID-JSFA665>3.0.CO;2-L

Mohammadi, K., Ranjbar, M., \& Targholizadeh, H. (2016). Synthesis and characterization photoluminescence properties of $\mathrm{Au} / \mathrm{GrO}$ nanocomposites by microwave method. Journal of Materials Science: Materials in Electronics, 1e5.https://doi.org/10.1007/s10854-016-4772-2

Prichapan, N., Klinkesorn, U., 2014. Factor affecting the properties of water-inoil-inwater emulsions for encapsulation of minerals and vitamins. Songklanakarin J. Sci.Technol. 36 (6), 651-661.

Peryam, D., Girardot, N. (1952). Advanced Taste-Test Method, Food Engineering, 24 (7). 58-61.

Rozes, N., Garbay, S., Denayrolles, M., \& Lonvaud-Funel, A. (1993). A rapid method for the determination of bacterial fatty acid composition. Letters in Applied Microbiology, 17(3), 126-131.https://doi.org/10.1111/i.1472765X.1993.tb01440.x

Seeram, N. P., Adams, L. S., Henning, S. M., Niu, Y., Zhang, Y., Nair, M. G., \& Heber, D. (2005). In vitro antiproliferative, apoptotic and antioxidant activities of punicalagin, ellagic acid and a total pomegranate tannin extract are enhanced in combination with other polyphenols as found in pomegranate juice. The Journal of nutritional biochemistry, 16(6), 360 367.https://doi.org/10.1016/j.jnutbio.2005.01.006

Snedecor, G.W., Cochran, W.G., 1980. Statistical Methods, 7 th. IBIT Public Co, Oxford.

Sobhaninia, M., Nasirpour, A., Shahedi, M., Golkar, A. (2017) Oil-in-water emulsions stabilized by whey protein aggregates: Effect of aggregate size, $\mathrm{pH}$ of aggregation and emulsion $\mathrm{pH}$. Journal of Dispersion Science and Technology, 38(9), 1366-1373.https://doi.org/10.1080/01932691.2016.1224719

Soleimanian, Y., Goli, S. A. H., Varshosaz, J., \& Sahafi, S. M. (2018) Formulation and characterization of novel nanostructured lipid carriers made from beeswax, propolis wax and pomegranate seed oil. Food chemistry, 244, 83 92.https://doi.org/10.1016/i.foodchem.2017.10.010

Suzuki, R., Noguchi, R., Ota, T., Abe, M., Miyashita, K., \& Kawada, T. (2001) Cytotoxic effect of conjugated trienoic fatty acids on mouse tumor and human monocytic leukemia cells. Lipids, 36(5), 477-482.https://doi.org/10.1007/s11745 001-0746-0

Tamjidi, F., Shahedi, M., Varshosaz, J., \& Nasirpour, A. (2014). Design and characterization of astaxanthin-loaded nanostructured lipid carriers. Innovative Food Science \& Emerging Technologies, 26, 366 374.https://doi.org/10.1016/j.ifset.2014.06.012 